\title{
Comparison of Competitive Ability of Cultivated Rice and Weedy Rice with Existing Weeds at Seedling Stage
}

\author{
Ratnasekera D. ${ }^{1}{ }^{*}$, Dilrukshi M.K.S. ${ }^{1}$, Himanda H.L.C. ${ }^{1}$ and Subhashi A.P.T. ${ }^{1}$ \\ ${ }^{I}$ Department of Agricultural Biology, Faculty of Agriculture, University of Ruhuna, \\ Kamburupitiya, Sri Lanka \\ *disnaratnasekera@gmail.com
}

\begin{abstract}
Weeds are the most important biological restraint in rice ecosystems which cause to reduce yield quantitatively and qualitatively. Weedy rice (Oryza sativa L. f. spontanea) is one of the most widespread and problematic weed, cause high yield losses when co-occurs with rice crop. Weedy rice is taxonomically classified as the same species as cultivated rice (O. sativa), but is strongly characterized by its seed shattering and dormancy, which assist to successfully compete with rice crop and other weeds.
\end{abstract}

The competition between crops and weeds is often affected by many factors, including cultivation methods and type of crop. The control of weedy rice has been difficult due to its morphological similarity to cultivated rice. Therefore the possible approach is use of pre eminent characters for rice crop improvement in breeding programs. This study was carried out in an experimental garden to evaluate the weed-crop competition under different cultivation conditions at seedling stage. Weedy rice and improved rice (variety At 362) were used under Randomized Complete Block Design (RCBD) with 3 replicates. 14-day old rice seedlings were used for transplanting plots.

The eight patterns of planting methods (T1-Improved rice transplanted with weeds, T2Improved rice transplanted without weeds, T3-Improved rice direct seeded with weeds, T4Improved rice direct seeded without weeds, T5-Weedy rice transplanted with weeds, T6Weedy rice transplanted without weeds, T7-Weedy rice direct seeded with weeds, T8-Weedy rice direct seeded without weeds.) were used as treatments. Plant height and number of tillers were measured at seedling stage.

The results of ANOVA revealed that the planting pattern, block effect and their interaction were significantly $(p<0.05)$ affected to both tested characters. The significantly $(p<0.05)$ highest plant height $(90.083 \pm 12.32501 \mathrm{~cm})$ and tiller number $(3.7083 \pm 1.428869)$ were observed in T6 (weedy rice transplanted plot without weeds) while lowest plant height (55.88 $\mathrm{cm}$ ) and tiller number (2.083) observed in T3 (improved rice direct seeded plot with weeds). All planting models, Weedy rice showed the higher performances compared to that of improved rice and both had poor performances at direct seeded field. The results suggest that weedy rice perform successfully with infestation of weeds in transplanted fields because of its enhanced competitive ability.

Keywords: Weeds, Weedy rice, Competition 